\title{
The Impact of Health on Work in China: A Study Using Pilot Survey Data
}

\author{
Yue-hua Zhang ${ }^{\mathrm{a}}$, Chu-Shiu Li ${ }^{\mathrm{b}}$, Chwen-Chi Liu ${ }^{\mathrm{c}}$ and \\ Sheng-Chang Peng ${ }^{c}$

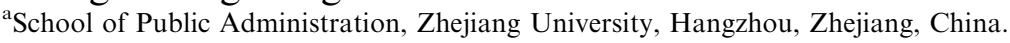 \\ E-mail: zhangyuehua@zju.edu.cn \\ ${ }^{\mathrm{b}}$ Department of International Business, Asia University, 500, Lioufeng Rd, Wufeng Taichung 41354, Taiwan. \\ E-mail: chushiu.li@gmail.com \\ ${ }^{c}$ Department of Risk Management and Insurance, Feng Chia University, Taichung, Taiwan. \\ E-mails: liuc@fcu.edu.tw; scpeng@fcu.edu.tw
}

Using the China Health and Retirement Longitudinal Study pilot survey, this paper analyses the relationship between work and health in middle-aged and elderly people in China. Using an instrumental variable estimation and simultaneous equation model, this study confirms that health and pension system do matter to employment.

The Geneva Papers (2013) 38, 857-870. doi:10.1057/gpp.2013.9

Keywords: health status; workplace; retirement; instrumental variable

Article submitted 1 February 2012; accepted 28 February 2013; published online 22 May 2013

\section{Introduction}

The emergence of an ageing and an increasingly elderly population is a worldwide phenomenon, especially in developed countries. Deterioration in health at older ages can result in early retirement, leaving households with inadequate income and increasing pressures on pension funds. The relationship between ill health and retirement has been investigated extensively in the literature for different countries such as Britain, ${ }^{1}$ Canada, ${ }^{2}$ the countries in Europe, ${ }^{3}$ the U.S. ${ }^{4}$ and others. In fact, ill health not only affects the time of retirement, but also reduces the probability of being employed in the first place. Therefore, developed countries must acquire a thorough understanding of the relationship between health and the workplace, and how it affects obtaining employment and work capability.

As the largest country in the world, China is also gradually facing this problem, although there is little research devoted to studies on this issue due to a lack of available data. Recently, however, China has released data from a pilot survey, the China Health and Retirement Longitudinal Study (CHARLS), which is the first systematic survey in the

\footnotetext{
${ }^{1}$ Disney et al. (2006) and Jones et al. (2010).

${ }^{2}$ Au et al. (2005).

${ }^{3}$ Garcia-Gomez (2011).

${ }^{4}$ Bound et al. (1999).
} 
Table 1 Source of old-age support for Chinese elderly

\begin{tabular}{|c|c|c|c|c|c|c|}
\hline $\begin{array}{l}\text { Source } \\
\text { Retired }\end{array}$ & Children & Savings & $\begin{array}{c}\text { Pension or } \\
\text { retirement salary }\end{array}$ & $\begin{array}{c}\text { Commercial } \\
\text { pension insurance }\end{array}$ & Other & Total \\
\hline YES & 384 & 29 & 174 & 3 & 34 & 624 \\
\hline$\%$ & 61.54 & 4.65 & 27.88 & 0.48 & 5.45 & 100 \\
\hline NO & 1,371 & 103 & 192 & 3 & 63 & 1,732 \\
\hline$\%$ & 79.16 & 5.95 & 11.09 & 0.17 & 3.64 & 100 \\
\hline Total & 1,755 & 132 & 366 & 6 & 97 & 2,356 \\
\hline$\%$ & 74.49 & 5.6 & 15.53 & 0.25 & 4.12 & 100 \\
\hline
\end{tabular}

country that resembles the U.S. Health and Retirement Study (HRS). Based on this unique data set, this paper examines the relationship between health and the workplace for the middle-aged and elderly in China. To be specific, it analyses the effect of health on the decision to work by taking into account the endogeneity of the self-perceived health status.

The decision for elderly to either keep working or retire early is often based on health: a healthy employee will usually choose to keep working and earn a salary, while one with poor health will often choose to retire. The previous literature broadly discusses similar topics, but most of the studies are based on the social systems and economic environments of developed countries, and therefore are not suitable for examining China. For example, financial incentives from a social security system are a major motivator for people seeking early retirement in developed countries. ${ }^{5}$ However, in China, retirement benefits are not very attractive, and a pension system has only recently been developed.

The pension system in China has, however, been improved since 1997. After several stages of undergoing reform, the design of the current system is based on three pillars and the financial funding is shared by the state, employers and employees. The first pillar, which is mandatory, consists of two tiers: a social pool financed by the employer that consists of a contribution rate of 20 per cent of wages, and an individual account with a rate of 8 per cent of wages. The expected replacement ratio is 59 per cent. $^{6}$ The second pillar is the enterprise annuity, which is required for employers but is voluntary for employees. The contribution (up to 4 per cent or more) from employers can be claimed as expenses. The third pillar is voluntary, individual pension saving. Given the expected pension structure, the current coverage rate is very low due to the diversity of regional situations. For example, at the time CHARLS was conducted, the coverage rate of the first pillar was 35 per cent in Zhejiang and 8.7 per cent in Gansu. ${ }^{7}$

Therefore, when asked the question in CHARLS, "On whom do you think you can rely for old-age support?" 61.54 per cent of those currently retired replied that they relied on their children, which seems to be the tradition for Chinese families (Table 1),

\footnotetext{
${ }^{5}$ See Au et al. (2005) and Garcia-Gomez (2011).

${ }^{6}$ Ebbers et al. (2009).

${ }^{7}$ National Bureau of Statistics of China (2009).
} 
while only 27.88 per cent said that they relied on a pension or retirement salary. These figures become even more extreme for those who are still working, namely, 79.16 and 11.09 per cent, respectively. In other words, financial incentives for early retirement in China are currently not a critical concern.

This paper contributes to the related literature by providing an alternative view of health in the workplace based on the Chinese work environment and identifies specific health factors that may influence the decision to work.

\section{Literature}

The relationship between health and work has been a relatively overlooked topic in studies on China, having only attracted attention in recent years. Wei investigates health, non-farm work and wage determination based on a 1993 Chinese nutrition survey (CHNS). ${ }^{8}$ The results from the Heckman model show that the effects of health on labour force participation and the probability of non-farm work are significantly positive.

Cao and Du study the connection between health and employment by focusing on urban residents. ${ }^{9}$ Using 2006 CHNS data, they reach the conclusion that health has a significantly positive effect on employment, although its effect on income is not significant. Tian uses data from CHARLS to examine the effects of health on labour force participation. ${ }^{10}$ By applying a simultaneous equations model, she concludes that good health significantly affects labour force participation. On the other hand, the reverse is also true in that working is good for a person's health.

Zhang analyses the effect of changes in health on labour supply and household income. ${ }^{11}$ Using data from CHNS, he discovers that lagged health conditions are significantly and positively related to current labour supply and household income. In addition, a person's resident status and gender play various roles. Urban dwellers and males easily quit due to poor health conditions, while rural people and females are more likely to increase their labour participation due to health improvements.

Most of the above studies have relied on the self-perceived health status used to explore similar subjects. However, none has taken into account the possible problems of measurement bias and endogeneity, with the exception of that by Tian, whose simultaneous equations model can take care of the endogeneity problem. ${ }^{10}$

The international literature pertaining to the topic of this research paper is broader and more sophisticated in terms of an econometric model and a dynamic data approach. For example, Bound et al. analyse the relationship between health and labour force participation by considering the behaviour of the labour force more completely when they include variations such as quitting one's job, changing one's job and the application for disability insurance. ${ }^{4}$ Using HRS data and having controlled for the lagged value of health, the authors argue that poor health is significantly related to leaving the labour force.

\footnotetext{
${ }^{8}$ Wei (2004).

${ }^{9} \mathrm{Cao}$ and Du (2010).

${ }^{10}$ Tian (2010).

11 Zhang (2011).
} 
Disney et al. use the British Household Panel Survey (BHPS) to explore the role of ill health on retirement decisions. ${ }^{12}$ Following the instrumental variable approach that Bound et al. propose ${ }^{4}$ the authors establish a measure of the health shock to predict retirement behaviour and find that both lagged health, and current health shocks affect employment decisions.

$\mathrm{Au}$ et al. examine the health and employment relationship for older Canadians. ${ }^{2}$ By focusing on the issues of endogeneity and measurement error that may be due to self-perceived health status, they compare the effects of several health indicators on employment. They confirm that health significantly affects the probability of employment for Canadians aged 50-64.

Using longitudinal data sets from Britain and Germany, Roberts, Rice and Jones estimate hazard models for the effect of health on early retirement among men and find that health is a key determinant of the retirement hazard for men in both sample countries. ${ }^{13}$ Citing policies that either provide financial incentives to encourage people to work until a greater age or raise the statutory retirement age, the authors argue that there is a need to improve the health of the workforce and to devote resources to those with health problems, thereby helping them to keep working.

By basing his study on the European Community Household Panel, Garcia-Gomez inspects the relationship between health shocks and the labour market for nine European countries. ${ }^{3}$ By using matching techniques, he confirms that health significantly affects the probability of employment. The estimates differ across countries due to differences in social security systems.

There are many benefits from using a dynamic data set in health and work research, as a transition in health status makes the measurement of the health shock possible. Therefore, the behaviour of switching or leaving employment is traceable. This study, however, uses the Chinese pilot survey that contains only one wave of data (details below) and therefore the analysis of transitions in health or employment is not possible. With this limitation, this research examines the relationship between the health stock and work using cross-sectional data. A well-designed questionnaire similar to HRS can still detect intertemporal behaviour by asking about past and present health/work situations. The effects of specific health problems on work decisions are thus emphasised.

\section{Methodology}

\section{Data}

The data in this paper are obtained from the pilot survey, CHARLS, which provides an overview of the elderly population in two Chinese provinces, namely, Gansu and Zhejiang, which are chosen because they represent poor inland and rich coastal regions, respectively. Using stratification sampling at the county, neighbourhood, household and respondent levels, CHARLS interviewed 2,685 individuals aged 45 years old or more from 1,570 households. ${ }^{14}$ The detailed data include demographic

\footnotetext{
${ }^{12}$ Disney et al. (2006).

${ }^{13}$ Roberts et al. (2010).

${ }^{14}$ Zhao et al. (2009).
} 
background, family, health status and level of functioning, health care and insurance, work, retirement and pension, income, expenditures, and assets. CHARLS's designation is similar to that of the HRS in the US, which is widely used in various research disciplines, the key variable being self-perceived health status. To construct a focused sample, this research excludes those who did not answer questions regarding health status and obtains 2,388 (88.9 per cent) observations.

The variables used in this paper are shown in the Appendix.

\section{Method}

To analyse the effects of health on employment, a good measure of health is crucial. A common measure is the self-perceived health status, which appears in many standard questionnaires, including CHARLS. However, potential problems from the biases often found in the self-perceived health status are well documented, the major concerns being subjective judgements and endogeneity. ${ }^{15}$ To deal with these issues, we first establish an objective health index and then adopt an instrumental variable method to estimate the relationship between health and employment. To check whether it is robust, we also build a simultaneous equations model and run a two-stage least squares estimation. The details are explained as follows.

Of the many alternatives for creating an objective health index, Bound et al. propose a measure that is suitable for the data available in this paper. ${ }^{4}$ Instead of directly using the self-perceived health status, this paper utilises the estimate of a health equation in which the self-perceived health status is the dependent variable, and the explanatory variables are detailed health conditions which include various diseases and functional limitations that affect daily life. As in the instrumental variable method, an ordered probit model obtains the predicted value of health status and then uses it as an objective health measure to analyse the employment issue. The estimated equation is

$$
H_{i}^{*}=\gamma^{\prime} Z_{i}+\varepsilon_{i}
$$

where $H_{i}^{*}$ is the latent and continuous measure of health status perceived by respondent $i ; Z_{i}$ is the vector of objective health conditions; $\gamma$ is the vector of parameters to be estimated; and $\varepsilon_{i}$ is the error term.

The latent measure is not observable. The respondent's choice, $H_{i}$, from the survey is determined by the following rule:

$$
\begin{aligned}
H_{i}=1 & \text { if } \quad-\infty \leqslant H_{i}^{*} \leqslant \mu_{1} \text { (very poor), } \\
2 & \text { if } \quad \mu_{1}<H_{i}^{*} \leqslant \mu_{2} \text { (poor), } \\
3 & \text { if } \quad \mu_{2}<H_{i}^{*} \leqslant \mu_{3} \text { (fair), } \\
4 & \text { if } \quad \mu_{3}<H_{i}^{*} \leqslant \mu_{4} \text { (good), } \\
5 & \text { if } \quad \mu_{4}<H_{i}^{*} \leqslant \infty \text { (very good), }
\end{aligned}
$$

where the $\mu_{i}$ are thresholds to be estimated.

\footnotetext{
${ }^{15}$ See Au et al. (2005) and Bound et al. (1999).
} 
Following the procedure proposed in the literature, ${ }^{16}$ the predicted health indicator obtained from Eq. (1), $\hat{H}_{i}{ }^{*}$ is re-scaled to the $[0,1]$ interval by using the formula

$$
\tilde{H}_{i}^{*}=\frac{\hat{H}_{i}^{*}-\hat{H}^{\min }}{\hat{H}^{\mathrm{max}}-\hat{H}^{\mathrm{min}}},
$$

where $\hat{H}^{\text {max }}$ and $\hat{H}^{\text {min }}$ are the largest and the smallest predicted values, respectively. The relationship between health and employment can then be analysed by using the adjusted health indicator $\tilde{H}_{i}^{*}$ as the key covariate.

The second methodology concern is the endogeneity. Our main goal is to explore the effect of health on the decision to work. However, employment itself may also affect health status. In addition, there may be many unobserved variables that simultaneously influence both labour market outcomes and health. The mutual relationship between health and employment gives rise to an endogeneity problem. The natural solution is to find an instrumental variable that is closely related to health, yet has nothing to do with employment. Fortunately, in our questionnaire, there is a set of questions that looks into the intensity of any exercise, which can be used as the instrumental variable. It is well known that regular exercise is good for health; most importantly, exercise does not seem to directly affect employment. Therefore, we use the intensity of exercise to estimate the objective health status by including control variables other than disease and illness-related variables in the first stage. The predicted health status is used as the key covariate to estimate the choice of whether to work or not in the second stage.

In addition to the demographic variables, we have added a "transfer payment received from children" in particular. We expect it to have a negative effect on employment, as routine financial support from children will reduce the need to find a job. However, a transfer payment might be endogenous in that it is affected by the working status. Children are more likely to make larger transfer payments to parents without a job. Therefore, we run the model that replaces "transfer payment" by a predicted value using the "number of children" as the explanatory variable.

To explore the relationship between pensions and working status, we have also included a dummy variable to represent whether the respondent receives a pension or not.

To check for robustness, we run a two-stage least squares estimation by considering that both work choice and health status mutually affect each other. There are two simultaneous equations that include two endogenous variables, namely, health and employment. The explanatory variables for the health equation are demographic characteristics and related variables other than diseases, such as the intensity of exercise. For the employment equation, the variables used are the same as before.

\section{Results}

Before analysing the main problem, this research first briefly compares the selfperceived health status among the various groups. Based on data from CHARLS, the

\footnotetext{
${ }^{16}$ See Cutler and Richardson (1997) and Groot (2000).
} 
Table 2 Self-perceived health status in workplace

\begin{tabular}{|c|c|c|c|c|c|c|c|c|c|c|c|c|}
\hline \multirow{2}{*}{ Work type } & \multicolumn{12}{|c|}{ Self-perceived health status } \\
\hline & \multicolumn{2}{|c|}{ Very poor (\%) } & \multicolumn{2}{|c|}{ Poor $(\%)$} & \multicolumn{2}{|c|}{ Fair $(\%)$} & \multicolumn{2}{|c|}{ Good $(\%)$} & \multicolumn{2}{|c|}{ Very $\operatorname{good}(\%)$} & \multicolumn{2}{|c|}{ Total (\%) } \\
\hline \multicolumn{13}{|l|}{ Female } \\
\hline Non-worker & 61 & 12.7 & 133 & 27.6 & 178 & 36.9 & 88 & 18.3 & 22 & 4.6 & 482 & 100 \\
\hline Farmer & 39 & 7.7 & 142 & 28.2 & 211 & 41.9 & 89 & 17.7 & 23 & 4.6 & 504 & 100 \\
\hline Self-employed & 3 & 2.7 & 12 & 10.8 & 48 & 43.2 & 36 & 32.4 & 12 & 10.8 & 111 & 100 \\
\hline Employed & 1 & 0.7 & 23 & 14.8 & 75 & 48.4 & 42 & 27.1 & 14 & 9.0 & 155 & 100 \\
\hline Total & 104 & 8.3 & 310 & 24.8 & 512 & 40.9 & 255 & 20.4 & 71 & 5.7 & 1,252 & 100 \\
\hline \multicolumn{13}{|l|}{ Male } \\
\hline Non-worker & 32 & 11.6 & 65 & 23.6 & 112 & 40.7 & 53 & 19.3 & 13 & 4.7 & 275 & 100 \\
\hline Farmer & 28 & 5.3 & 116 & 21.8 & 236 & 44.3 & 121 & 22.7 & 32 & 6.0 & 533 & 100 \\
\hline Self-employed & 4 & 2.9 & 20 & 14.5 & 56 & 40.6 & 35 & 25.4 & 23 & 16.7 & 138 & 100 \\
\hline Employed & 2 & 1.1 & 11 & 5.8 & 89 & 46.8 & 70 & 36.8 & 18 & 9.5 & 190 & 100 \\
\hline Total & 66 & 5.8 & 212 & 18.7 & 493 & 43.4 & 279 & 24.6 & 86 & 7.6 & 1,136 & 100 \\
\hline
\end{tabular}

self-perceived health status is closely related to working status. Table 2 illustrates this situation by separating the whole sample by gender into four subgroups: non-worker, farmer, self-employed and employed. Relatively speaking, female respondents have a higher percentage of "Very poor" and "Poor" self-perceived health statuses in the nonworker (40.3 per cent) and farmer (35.9 per cent) categories. By contrast, only small percentages (13.5-15.5 per cent) of those who are self-employed and employed rated themselves as unwell. Of the responses from females in all groups, "Fair" seems to account for the largest share of around 40 per cent. Added together, the percentages of those who rated their health as "Good" and "Very good" in the self-employed and employed groups are 43.2 and 36.1 per cent, respectively, while the percentages for those in the non-worker and farmer groups are 22.9 and 22.3 per cent, respectively. In general, the self-employed and employed female respondents have a superior self-rated health status in comparison with non-workers and farmers. A similar situation can be seen for male respondents. However, the percentages of males who rated themselves as "Good" and "Very good" are much higher than they are for females, indicating that males were more likely to rate themselves as having better health.

This study examines the effects of health on work by taking into account the endogeneity problem of self-perceived health status as it may be connected with the ability to work. Based on the instrumental variable estimation found in the work of Bound et al. and Au et al., ${ }^{17}$ Eq. (1) in the previous section obtains a more objective health indicator $(\mathrm{OHI})$ by including detailed health conditions. Table 3 shows the estimated coefficients with respect to various health problems. Among them, the common sources that affect OHI for both males and females are Hypertension, Chronic Lung Disease, Heart Attack, Digestive Disease, Arthritis or Rheumatism, Signal_ill, Other_ill, Functional Limitation and Unhappiness. Male-only problems

${ }^{17}$ Bound et al. (1999) and Au et al. (2005). 
Table 3 Estimation of objective health status (OHI)

\begin{tabular}{|c|c|c|c|c|}
\hline \multirow{2}{*}{$\begin{array}{l}\text { Ordered probit regression } \\
\text { Health situation }\end{array}$} & \multicolumn{2}{|c|}{ Female } & \multicolumn{2}{|c|}{ Male } \\
\hline & Coefficient & Standard error & Coefficient & Standard error \\
\hline 1. Hypertension & $-0.307 * * *$ & 0.072 & $-0.301 * * *$ & 0.079 \\
\hline 2. High cholesterol & 0.063 & 0.111 & 0.192 & 0.123 \\
\hline 3. Diabetes & -0.083 & 0.163 & -0.245 & 0.161 \\
\hline 4. Cancer & -0.214 & 0.241 & 0.091 & 0.123 \\
\hline 5. Chronic lung disease & $-0.273 * * *$ & 0.098 & $-0.459 * * *$ & 0.101 \\
\hline 6. Liver disease & -0.091 & 0.184 & $-0.246^{*}$ & 0.149 \\
\hline 7. Heart attack & $-0.211 * *$ & 0.102 & $-0.424 * * *$ & 0.122 \\
\hline 8. Stroke & -0.116 & 0.220 & $-0.430 * *$ & 0.219 \\
\hline 9. Kidney disease & -0.109 & 0.181 & $-0.303 * *$ & 0.147 \\
\hline 10. Digestive disease & $-0.357 * * *$ & 0.071 & $-0.416 * * *$ & 0.078 \\
\hline 11. Psychiatric problems & -0.551 & 0.442 & -0.479 & 0.510 \\
\hline 12. Memory-related disease & 0.289 & 0.228 & 0.115 & 0.333 \\
\hline 13. Arthritis or rheumatism & $-0.170^{* *}$ & 0.073 & $-0.288 * * *$ & 0.083 \\
\hline Signal ill & $-0.331 * * *$ & 0.117 & $-0.285^{* *}$ & 0.113 \\
\hline Other ill & $-0.287 * * *$ & 0.068 & $-0.226 * * *$ & 0.075 \\
\hline Functional limitation & $-0.135 * * *$ & 0.015 & $-0.150 * * *$ & 0.016 \\
\hline Unhappiness & $-0.087 * * *$ & 0.014 & $-0.136 * * *$ & 0.018 \\
\hline Disorder & $-0.095 * * *$ & 0.032 & -0.052 & 0.041 \\
\hline /cut1 & -2.681 & 0.098 & -3.049 & 0.116 \\
\hline /cut2 & -1.451 & 0.069 & -1.840 & 0.073 \\
\hline /cut3 & -0.128 & 0.059 & -0.368 & 0.059 \\
\hline /cut4 & 0.959 & 0.071 & 0.751 & 0.069 \\
\hline Pseudo $R^{2}$ & \multicolumn{2}{|c|}{0.132} & \multicolumn{2}{|c|}{0.146} \\
\hline Log pseudo-likelihood & \multicolumn{2}{|c|}{-1526.238} & \multicolumn{2}{|c|}{-1340.103} \\
\hline$N$ & \multicolumn{2}{|c|}{1252} & \multicolumn{2}{|c|}{1136} \\
\hline
\end{tabular}

$* p<0.10 ; * * p<0.05 ; * * * p<0.01$.

include Liver Disease (10 per cent level), Stroke (5 per cent level) and Kidney Disease (5 per cent level), which all significantly lower OHI. One factor, Disorder, is significant for females only at the 1 per cent level.

Table 4 contains the results of the analysis of the health-work relationship. Based on the procedures described in the previous section, we run a Tobit regression in the first stage to predict an objective health index by using physical activities as instrumental variables. The predicted health index is the key variable used in the second stage to explain the decision to work. We present the key results from the second stage in Table 4. As expected, better health is positively related to the probability of working. The estimated coefficients are significant at the 1 per cent level for males and females. The estimated results of the control variables provide additional information regarding the choice to work. ${ }^{18}$ Since the retirement ages are different for males (60)

${ }^{18}$ We have tried to include two more variables as suggested by one reviewer, namely, age of spouse and spouse retirement status. The results show that the age of the spouse has no effect on retirement, while the retirement of the spouse significantly and positively affects the retirement decision. However, with the 
Table 4 Probit regression: Health and work

\begin{tabular}{|c|c|c|}
\hline Dependent variable: Work or not & (1) Male & (2) Female \\
\hline $\mathrm{OHI}$ & $\begin{array}{l}14.80 * * * \\
(1.322)\end{array}$ & $\begin{array}{l}11.53^{* * *} \\
(1.312)\end{array}$ \\
\hline Age below 50 & $\begin{array}{c}0.209 \\
(0.213)\end{array}$ & $\begin{array}{l}0.528 * * * \\
(0.121)\end{array}$ \\
\hline Age 60 and above & $\begin{array}{c}-0.721 * * * \\
(0.114)\end{array}$ & $\begin{array}{c}-0.545^{* * *} \\
(0.0994)\end{array}$ \\
\hline Primary school & $\begin{array}{c}0.165 \\
(0.120)\end{array}$ & $\begin{array}{c}-0.202^{* *} \\
(0.101)\end{array}$ \\
\hline Middle school & $\begin{array}{c}0.0526 \\
(0.139)\end{array}$ & $\begin{array}{c}0.0711 \\
(0.155)\end{array}$ \\
\hline Married & $\begin{array}{l}0.263 * * \\
(0.127)\end{array}$ & $\begin{array}{c}0.174 \\
(0.112)\end{array}$ \\
\hline Rural & $\begin{array}{l}1.298^{* * * *} \\
(0.142)\end{array}$ & $\begin{array}{l}1.614 * * * \\
(0.133)\end{array}$ \\
\hline Transfer payments & $\begin{array}{c}-0.0000567 \\
(0.00209)\end{array}$ & $\begin{array}{r}-0.00177 \\
(0.00188)\end{array}$ \\
\hline Zhejiang & $\begin{array}{c}-1.212 * * * \\
(0.146)\end{array}$ & $\begin{array}{c}-0.966^{* * *} \\
(0.131)\end{array}$ \\
\hline Pension & $\begin{array}{c}-0.603 * * * \\
(0.222)\end{array}$ & $\begin{array}{c}-1.018^{* *} \\
(0.425)\end{array}$ \\
\hline Zhejiang $\times$ Pension & $\begin{array}{c}0.382 \\
(0.274)\end{array}$ & $\begin{array}{l}0.937 * * \\
(0.465)\end{array}$ \\
\hline Constant & $\begin{array}{c}-11.18 * * * \\
(1.552)\end{array}$ & $\begin{array}{c}-10.48^{* * * *} \\
(1.500)\end{array}$ \\
\hline$N$ & 1136 & 1252 \\
\hline Log pseudo-likelihood & 3100.68 & 3298.32 \\
\hline
\end{tabular}

Standard errors in parentheses.

${ }^{*} p<0.10 ; * * p<0.05 ; * * * p<0.01$.

and females (50) in China, we build the regression model by using three age groups (below 50, 50-59, and 60 and above). For males, there is no significant difference in the tendency to work between the group aged below 50 and that aged 50-59. However, the female group aged below 50 is more likely to work than the reference group (50-59) at the 1 per cent level of significance. The results perfectly reflect the social practices in China. Transfer payments received from children reduce the probability of going to work. However, the coefficients are insignificant both for males and females. Primary education (grades 1-6) has a significantly negative effect on females, but not on males. The reference group is illiterate. A rational conjecture is that working females usually have a lower level of education and their field of employment is not related to their education. The data further verify this assumption, as it reveals that 
866

71.23 per cent of the female farmers are illiterate, compared with only 30.39 per cent of male farmers. In other words, the majority of females never go to school. This fact causes the estimated coefficients of education to be negative.

It is also interesting to see that individuals with rural household status are more likely to work than those without, and that those who reside in Zhejiang are less likely to work. In China, rural household status reflects "hukou" registration only and does not necessarily represent the real type of residency. However, the negative effect for Zhejiang indicates that the probability of respondents working in a more developed region is significantly lower. The disparity in economic environments might be the main reason.

To explore the relationship between pensions and working status, we have included a dummy variable to represent whether the respondent receives a pension or not. In addition, we have also added an interaction term "Zhejiang $\times$ Pension" to examine the impact of the pension on work in different regions. The results show that those who receive a pension are less likely to work again; the coefficients are significant both for males and females. Respondents in Zhejiang are less likely to work. However, those females receiving a pension but who live in Zhejiang are significantly more likely to work. It seems that having retired does not prevent those respondents from working again. This fact raises two interesting issues. First, it might be too early for females to retire at 50 for a developed province such as Zhejiang. Females prefer to work beyond the official mandatory retirement age. Second, compared with the wage received before retiring, a pension might not meet the needs of those retired workers in Zhejiang. Therefore, finding another job after retiring becomes necessary. The implication of our findings suggests that a diversified retirement and pension policy based on regional discrepancy seems to be needed in China.

For the robustness check, we build a simultaneous equations model to explore the decision to work. In the first equation, we perform a regression with the objective health status depending on the choice to work or not, demographic variables and health-related factors. In the second equation, the objective health status and family economic variables are used to explain the probability of work. The two key variables, objective health status and work, are mutually determined. Table 5 presents the results of a two-stage estimation in which one of the endogenous variables is continuous and the other is dichotomous.

Panel A in Table 5 shows that work might reduce health status, although the effects are not significant for both males and females. The age effect is also insignificant as we include health variables such as the number of diseases (Condition) and Functional limitation, both of which are closely related to age. It is rational to expect that those with a greater number of diseases and Functional limitation are far less healthy. The married status is good for health, which is also consistent with the health literature. The income effect is only significant for females. The results in Panel B indicate that those with better health are more likely to work, while older individuals are significantly less likely to work. Other estimated results are similar to the findings obtained from the instrumental variable estimation. The effect of transfer payments on the decision regarding work is significantly negative for both males and females, but it is insignificant. The coefficients of the interaction term of "Zhejiang $\times$ Pension" are significant for both males and females, and are even more pronounced than for the results based on using instrumental variables. 
Table 5 Health and work

\begin{tabular}{|c|c|c|c|c|}
\hline \multirow[t]{2}{*}{ Simultaneous equations } & \multicolumn{2}{|c|}{$\begin{array}{c}\text { Model } 1 \\
\text { Male }\end{array}$} & \multicolumn{2}{|c|}{$\begin{array}{c}\text { Model } 2 \\
\text { Female }\end{array}$} \\
\hline & Coefficient & Standard error & Coefficient & Standard error \\
\hline \multicolumn{5}{|l|}{ Panel A: First equation } \\
\hline \multicolumn{5}{|l|}{ Dependent variable: $O H I$} \\
\hline Work or not & -0.004 & 0.010 & -0.012 & 0.008 \\
\hline Age below 50 & 0.004 & 0.006 & 0.006 & 0.006 \\
\hline Age 60 and above & -0.002 & 0.010 & 0.010 & 0.008 \\
\hline Married & $0.024 * * *$ & 0.006 & $0.017 * * *$ & 0.006 \\
\hline Rural & -0.020 & 0.013 & 0.011 & 0.015 \\
\hline Zhejiang & $0.024 * * *$ & 0.006 & $0.026 * * *$ & 0.007 \\
\hline Condition & $-0.058 * * *$ & 0.002 & $-0.059 * * *$ & 0.002 \\
\hline Functional limitation & $-0.032 * * *$ & 0.002 & $-0.034 * * *$ & 0.001 \\
\hline $\log ($ income $)$ & 0.001 & 0.001 & $0.002 * *$ & 0.001 \\
\hline Constant & $0.899 * * *$ & 0.011 & $0.875 * * *$ & 0.010 \\
\hline $\operatorname{Adj} R^{2}$ & 0.7711 & & 0.7938 & \\
\hline \multicolumn{5}{|c|}{ Panel B: Second equation } \\
\hline \multicolumn{5}{|c|}{ Dependent variable: Work or not } \\
\hline $\mathrm{OHI}$ & $2.999 * * *$ & 0.410 & $2.193 * * *$ & 0.347 \\
\hline Age below 50 & 0.148 & 0.182 & $0.467 * * *$ & 0.128 \\
\hline Age 60 and above & $-0.795^{* * *}$ & 0.109 & $-0.751 * * *$ & 0.098 \\
\hline Married & $0.232^{*}$ & 0.125 & 0.139 & 0.112 \\
\hline Primary school & $0.261 * *$ & 0.113 & $-0.191^{*}$ & 0.103 \\
\hline Middle school & 0.120 & 0.136 & -0.009 & 0.159 \\
\hline Rural & $0.888 * * *$ & 0.131 & $1.199 * * *$ & 0.139 \\
\hline Transfer payments & -0.001 & 0.002 & -0.002 & 0.002 \\
\hline Zhejiang & $-0.400^{* * *}$ & 0.108 & $-0.463 * * *$ & 0.099 \\
\hline Pension & $-0.716^{* * *}$ & 0.220 & $-1.134 * * *$ & 0.391 \\
\hline Zhejiang $\times$ Pension & $0.486^{*}$ & 0.272 & $1.042 * *$ & 0.427 \\
\hline Constant & $-2.429 * *$ & 1.200 & $-3.034 * * *$ & 1.139 \\
\hline Pseudo $R^{2}$ & \multicolumn{2}{|c|}{0.2389} & \multicolumn{2}{|c|}{0.2423} \\
\hline$N$ & \multicolumn{2}{|c|}{1136} & \multicolumn{2}{|c|}{1252} \\
\hline
\end{tabular}

$* p<0.10 ; * * p<0.05 ; * * * p<0.01$.

To sum up, based on two different estimation strategies, we receive consistent results for the relationship between health and work, finding that health status plays a key role in the decision to work.

\section{Conclusion}

Using the CHARLS pilot survey, this paper analyses the relationship between work and health for middle-aged and elderly people in China. We construct a more objective health indicator by including detailed health conditions to compare the health-related 
problems among non-workers, farmers, the self-employed and the employed. The key issue is the decision to work.

Based on the instrumental variable estimation and simultaneous equation model, we obtain consistent results to show that better health is positively associated with the probability of working. There is no significant difference for males in the tendency to work between the group aged below 50 and that aged 50-59. For females, the group aged below 50 is more likely to work than the reference group (50-59). In addition, those females receiving a pension but who live in Zhejiang are significantly more likely to work. A diversified retirement and pension policy based on regional discrepancies seems to be needed in China. Although there are no panel data to provide transition patterns in health as well as in employment, the results from this study confirm that health does matter to employment.

\section{Acknowledgements}

Financial supports from National Natural Science Foundation of China (grant no. 70873102) and Zhejiang Social Science Foundation Research Plan (grant no. 12JDLB02Z) are gratefully acknowledged.

\section{References}

Au, D., Crossley, T. and Schellhorn, M. (2005) 'The effect of health changes and long-term health on the work activity of older Canadians', Health Economics 14(10): 999-1018.

Bound, J., Schoenbaum, M., Stinebrickner, T. and Waidmann, T. (1999) 'The dynamic effects of health on the labor force transitions of older workers', Labour Economics 6(2): 179-202.

Cao, G. and Du, W. (2010) 'Health effects of employment and income effects: Based on Heckman's test', Inquiry into Economic Issues 1: 134-138, [in Chinese].

Cutler, D. and Richardson, E. (1997) 'Measuring the health of the United States population', Brookings Papers on Economic Activity: Microeconomics, 217-271.

Disney, R., Emmerson, C. and Wakefield, M. (2006) 'Ill health and retirement in Britain: A panel data-based analysis', Journal of Health Economics 25(4): 621-649.

Ebbers, H., Hagendijk, R. and Smorenberg, H. (2009) China's Pension System, Positioning Paper, Rijswijk, NL: Nyenrode Business University.

Garcia-Gomez, P. (2011) 'Institutions, health shocks and labour market outcomes across Europe', Journal of Health Economics 30(1): 200-213.

Groot, W. (2000) 'Adaptation and scale of reference bias in self-assessments of quality of life', Journal of Health Economics 19(3): 403-420.

Jones, A.M., Rice, N. and Roberts, J. (2010) 'Sick of work or too sick to work? Evidence on self-reported health shocks and early retirement from the BHPS', Economic Modelling 27(4): 866-880.

National Bureau of Statistics of China (2009) China Statistical Yearbook 2009, Beijing: China Statistics Press.

Roberts, J., Rice, N. and Jones, A.M. (2010) 'Early retirement among men in Britain and Germany: How important is health?' The Geneva Papers on Risk and Insurance-Issues and Practice 35(4): 644-667.

Tian, Y. (2010) 'Effect of health on labor force participation of the senior citizens in China', Journal of Shanxi Finance and Economics University 32(3): 1-7.

Wei, Z. (2004) 'The role of health on off-farm employment and wage decision', Economic Research Journal 2: 64-74 [in Chinese].

Zhang, C. (2011) 'Empirical analysis on impact of health change on labor supply and income', Economic Review 170(4): 79-88, [in Chinese].

Zhao, Y., Strauss, J., Park, A. and Sun, Y. (2009) China Health and Retirement Longitudinal Study, Pilot, User's Guide, National School of Development, Peking University. 


\section{Appendix}

Table A1 List of variables

Self-perceived health status OHI

Farmer

Self-employed

Employed

Age below 50

Age 60 and above

Illiterate

Primary school

Middle school

Married

Transfer payments

Signal ill

Hypertension

High cholesterol

Diabetes

Cancer

Chronic lung diseases

Liver disease

Heart attack

Stroke

Kidney disease

Digestive disease

Psychiatric problems

Memory-related disease

Arthritis or rheumatism

Condition

Accident

Other ill

Functional limitation

Unhappiness

Disorder

Physical activity—High intensity

Physical activity-Moderate intensity

Physical activity_-Walking

Log(income)

Pension

Rural

Zhejiang 5-very good, 4-good, 3-fair, 2-poor and 1-very poor

Predicted health stock

1 if respondent is a farmer, 0 otherwise

1 if respondent is self-employed, 0 otherwise

1 if respondent is employed, 0 otherwise

The age of the respondent is below 50

The age of respondent is 60 or above

1 if respondent is illiterate, 0 otherwise (reference category)

1 if respondent has had primary school education, 0 otherwise

1 if respondent has had middle school education, 0 otherwise

1 if married, 0 otherwise

Transfer payments received from children in the last year (in 1000RMB)

1 if respondent has at least one positive answer out of five questions about signals of illness, 0 otherwise

1 if respondent has Hypertension, 0 otherwise

1 if respondent has High cholesterol, 0 otherwise

1 if respondent has Diabetes, 0 otherwise

1 if respondent has Cancer, 0 otherwise

1 if respondent has Chronic lung diseases, 0 otherwise

1 if respondent has Liver disease, 0 otherwise

1 if respondent has had a Heart attack, 0 otherwise

1 if respondent has had a Stroke, 0 otherwise

1 if respondent has Kidney disease, 0 otherwise

1 if respondent has Digestive diseases, 0 otherwise

1 if respondent has Psychiatric problems, 0 otherwise

1 if respondent has Memory-related diseases, 0 otherwise

1 if respondent has Arthritis or rheumatism, 0 otherwise

The number of diseases the respondent has out of the above 13 diseases

1 if respondent has been in a traffic accident, 0 otherwise

1 if respondent has other illnesses not listed above, 0 otherwise

The number of physical problems respondent has out of 17 daily life activities

A total score ranging from 0 to 10 , a higher score indicating a bad mood obtained from a group of 10 questions

A total score ranging from 0 to 6 , a higher score indicating disorder obtained from a group of 6 questions

1 if in a usual week, respondent does activities that make breathing much harder than normal and may include heavy lifting, digging, plowing, aerobics, fast bicycling, or cycling with a heavy load, at least $10 \mathrm{~min}$ at a time; 0 otherwise.

1 if in a usual week, respondent does activities that make breathing somewhat harder than normal and may include carrying light loads, bicycling at a regular pace, or mopping the floor, at least $10 \mathrm{~min}$ at a time; 0 otherwise.

1 if in a usual week, respondent walks, including at work and at home, from place to place, and any other walking that might be solely for recreation, sport, exercise, or leisure; 0 otherwise.

Natural log of individual income

1 if respondent has received pension, 0 otherwise

1 if respondent has rural household status, 0 otherwise

1 if respondent lives in Zhejiang province, 0 otherwise 


\section{About the Authors}

Yue-hua Zhang is Associate Professor, School of Public Administration, Zhejiang University, Hangzhou, Zhejiang, China.

Chu-Shiu Li is Professor, Department of International Business, Asia University, Taichung, Taiwan.

Chwen-Chi Liu is Professor, Department of Risk Management and Insurance, Feng Chia University, Taichung, Taiwan.

Sheng-Chang Peng is Post Doctor, Department of Risk Management and Insurance Feng Chia University, Taichung, Taiwan. 